\title{
COMPARATIVE STUDIES ON THE PHYSIOCHEMICAL PROPERTIES, PHENOLIC COMPOUNDS AND ANTIOXIDANT ACTIVITIES IN 13 JAPANESE PLUM CULTIVARS GROWN IN THE SUBTROPICAL REGION OF CHINA
}

\author{
YU, X. M. ${ }^{1}$ - RizWAN, H. M. ${ }^{1}-$ LI, P. ${ }^{1}-$ LUO, S. X. ${ }^{2}-$ ShERAMETI, I. ${ }^{3}$ - WU, W. F. ${ }^{4}-$ LIN J. ${ }^{5}-$ \\ ZHENG, S. X. $.^{5}-$ OELMÜLlER, R. ${ }^{3}-$ CHEN, F. X. ${ }^{1 *}$ \\ ${ }^{1}$ Institute of Subtropical Fruit, Fujian Agriculture and Forestry University, Fuzhou 350002,
} China

${ }^{2}$ Economic Crop Technology Extension Station, Agriculture Department, Liancheng, Fujian Province 366200, China

${ }^{3}$ Institute of General Botany and Plant Physiology, Friedrich-Schiller-University Jena, 07743 Jena, Germany

${ }^{4}$ Lushan Botanical Garden, Chinese Academy of Sciences, Jiujiang, Jiangxi 332900, China

${ }^{5}$ Detection and Analysis Section, Disease Prevention and Control Center, Fuzhou 350004, China

*Corresponding author

e-mail: cfaxing@126.com

(Received $26^{\text {th }}$ Sep 2019; accepted $8^{\text {th }}$ Jan 2020)

\begin{abstract}
The physiochemical parameters and antioxidant properties of plum cultivars, grown in subtropical regions of China are little known. However, in this comparative study, these properties of 6 landraces and 7 introduced cultivars showed evaluated. The major nonvolatile constituents were a significant difference among cultivars. Color parameter values were strongly influenced by cyanidin 3-Oglucoside and cyanidin 3-O-rutinoside. Remarkably high antioxidant activity, high total phenolic, and ascorbic acid contents were found in black or purple flesh genotypes. Catechinic acid, the most important phenolic acid in Japanese plum, together with vanillic acid, caffeic acid and syringic acid, accounted for $>96 \%$ of the total phenolic content. The total phenolics and ascorbic acid concentration revealed significant contributions to antioxidant capacity detected by $\alpha$, $\alpha$-diphenyl- $\beta$-picrylhydrazyl (DPPH), $\left(\mathrm{r}=0.78^{* *}, 0.73^{* *}\right)$ and ferric reducing antioxidant power (FRAP) $\left(\mathrm{r}=0.74^{* *}, 0.57^{*}\right)$. Moreover, there was a clear correlation between the total phenolic compounds and the ascorbic acid content $\left(\mathrm{r}=0.76^{* *}\right)$. Comparison of physicochemical characteristics and antioxidant profiles revealed that both introduced cultivars and landraces had good adaptability in the subtropical region.
\end{abstract}

Keywords: Prunus salicina Lindl, chemical compounds, nutrient content, subtropical cultivation, correlation analysis

\section{Introduction}

People consume fruits not only for their taste, but also their vital nutritional content (Liu, 2013), strong antioxidants and health promotion capabilities (Dai and Mumper, 2010; Goodarzi et al., 2018). Bioactive compounds including phenolics, anthocyanins and phytochemicals as well as vitamins $\mathrm{E}$ and $\mathrm{C}$ are considered to be beneficial properties of fruits (Mirmiran et al., 2009; Wang et al., 2018). Hence, a great deal of research has been carried out, in order to improve the quantity and quality of bioactive compounds in commonly consumed fruits. 
Plum (Prunus salicina Lindl) commonly known as Japanese plum, is an important stone fruit crop commercially grown in China, Spain and USA. China ranks first in plum production ( $\mathrm{Li}$ et al., 2015; Vlaic et al., 2018). Likewise, other fruits, various kinds of polyphenolic compounds such as phenolic acids, flavonols, anthocyanins (Turturică et al., 2018) and antioxidant activities have been identified in plum (Gil et al., 2002). Plum are good source of antioxidant that protects from biomolecular damage including aging caused by free radicals (Cefali et al., 2018). However, European plums (Prunus domestica L.) and Japanese plums (Prunus salicina Lindl.) have several different concentrations of phytochemicals, nutritional properties and antioxidant activities (Arion et al., 2014; Fanning et al., 2014; Jaiswal et al., 2013). Different cultivars have a greater variation of phenolic composition and concentration under various environmental conditions (Bochi et al., 2015; Wang et al., 2018). Several reports have been found on Japanese plum cultivars focusing on large size and homogeneous color (red, purple or yellow) (Lozano et al., 2009). Recently, more attentions have been focused on the functional properties of plum, their reasonable source of dietary-fiber, ascorbic acid, phenolic compounds, anthocyanins and other compounds with antioxidant properties (Fanning et al., 2014; Jaiswal et al., 2013; Kim et al., 2003).

In the past 20 years, many plum cultivars such as Blackamber, Wickson, Fiar, and Methely have been introduced, in order to enhance the plum production scale. Most of the plums are adapted to subtropical regions of Southeastern China. However, little information is available about the phytochemical properties of Chinese genotypes growing in subtropical regions of China (Byrne et al., 2000; Liu et al., 2007). Assuming that physicochemical characteristic, phenolic compounds and antioxidant properties of different Japanese Plums cultivars are influenced in subtropical regions. The main objectives of this study were to analyze the physicochemical characteristics, phenolic compounds and antioxidant properties of 13 Japanese plum cultivars grown in southeastern China.

\section{Materials and methods}

\section{Plant materials}

Fruit samples of 13 plum cultivars were harvested at commercial maturity stage during early June to end of August from Fujian Agriculture and Forestry Experiment Station Orchard at the hillock reservoir of Gutian county, Fujian, located in Southeastern China (N26³8'56.67', E118 49'1.02', Elevation: $323 \mathrm{~m}$ ). The daily effective accumulated temperature is $>10^{\circ} \mathrm{C}$, and the annual average rainfall is about $5000 \mathrm{~mm}$. Among 13 cultivars, 7 were introduced (Friar, Gariota, Blackamber, Santa Rosa, Elodrao, Methely, and Akihime) and 6 were landraces (Furongli, Hongnai, Yanzhili, and Xiguali as local cultivars of Fujian, Crown and Cuipingwannai were from the college of Horticulture, Fujian Agriculture and Forestry University. The dates of taking the samples are displayed in Table Al in the Appendix. After harvesting, fruits were immediately transported to the laboratory and sorted in a refrigerator up to $4{ }^{\circ} \mathrm{C}$, according to the uniformity of their firmness. Plums without stones were cut into several pieces and then stored at $-80{ }^{\circ} \mathrm{C}$ until extraction. To ensure the uniformity of frozen material before further experiments, the fruits were ground to a fine powder by using liquid nitrogen. 


\section{Chemical standards}

Standards for sucrose, glucose, fructose and sorbitol, as well as malic, citric, shikimic and fumaric acids were obtained from Fluka Chemical (New York, USA). Catechinic, vanillic, gallic, caffeic, syringic, ferulic and chlorogenic acids, quercetin, cyanidin 3-Oglucoside and cyanidin 3-O-glucoside were purchased from Sigma-Aldrich (Oslo, Norway).

\section{Gas chromatography-mass spectrometer (GC-MS) determination of sugar compounds and organic acids}

Organic acids and sugars were extracted according to the protocol described by Liu et al. (2007) and Glew et al. (2003) The extraction of derivatives was carried out by using the method of Jiao et al. (2010). $1 \mu \mathrm{l}$ of the derivative sample was injected into GC-MS using the split mode 50:1 and injector temperature was $230^{\circ} \mathrm{C}$. Ultra-pure helium served as carrier gas at the constant flow of $1.0 \mathrm{~mL} \cdot \mathrm{min}^{-1}$. The oven was programmed at the following profile: initial temperature of the column was $70{ }^{\circ} \mathrm{C}(5 \mathrm{~min}$ hold $)$, followed by an increasing the rate of $5{ }^{\circ} \mathrm{C} \cdot \mathrm{min}^{-1}$ to $310{ }^{\circ} \mathrm{C}$ and then hold for $1 \mathrm{~min}$. The mass operating parameters were: interface temperature was $250{ }^{\circ} \mathrm{C}$, ion trap temperature was $200{ }^{\circ} \mathrm{C}$, ion source was EI mode, electron energy was $70 \mathrm{eV}$, the solvent delay was $8 \mathrm{~min}$. All data were obtained from the full-scan mass spectra within the range of $50-600 \mathrm{amu}$. The organic acids and sugars were identified by comparing the retention times and mass spectral data with the corresponding standards. Concentrations were determined according to the calibration of external standard solution.

\section{High performance liquid chromatography (HPLC) analysis of phenolic compounds and anthocyanins}

Plum extraction was carried out by the method of Gil et al. (2002). Samples were filtered through a $0.45 \mu \mathrm{m}$ filter and then used for the analysis of phenolic compounds by HPLC (Kelebek et al., 2015). Anthocyanins were analyzed at $530 \mathrm{~nm}$ by HPLC (Usenik et al., 2008).

\section{Antioxidant activity evaluation}

$2 \mathrm{~g}$ sample was extracted with $15 \mathrm{ml}$ solution of $80 \%$ methanol $(\mathrm{v} / \mathrm{v})$ at $30{ }^{\circ} \mathrm{C}$, then by an ultrasonic extraction with the power of $300 \mathrm{~W}$ for $40 \mathrm{~min}$. Furthermore, it was centrifuged at the acceleration of $10000 \times \mathrm{g}$ for $10 \mathrm{~min}\left(4^{\circ} \mathrm{C}\right)$. For the analysis of the antioxidant activities of the plum fruits, combined supernatants of two replications were filtered by using a $0.45 \mu \mathrm{m}$ filter. Three methods, i.e., the $\operatorname{DPPH}(\alpha, \alpha$-diphenyl- $\beta$ picrylhydrazyl, DDPH) (Arion et al., 2014), $\operatorname{ABTS}(2, \quad 2$ '-azino-bis(3ethylbenzothiazoline-6-sulfonic acid), ABTS) (Maria do Socorro et al., 2010) and FRAP (ferric reducing antioxidant power) (Benzie and Strain, 1996) were used in order to test the antioxidant activity of the plum fruits.

\section{Statistical analysis}

Three replications were used for each treatment $(n=3)$ and statistical analysis were conducted by using SPSS software (version 21.0). Results were expressed as mean values \pm standard deviation (SD). To determine whether the bioactive compounds would contribute to the antioxidant capacity, Pearson's correlation coefficients were calculated at $\mathrm{p}<0.05$ and $\mathrm{p}<0.01$ confident levels for all variables. An analysis of 
variance was performed followed by Student's t-test (two-tailed distribution, unequal variance). Relationships between the physicochemical variables and either cultivar of $P$. salsida or antioxidants capacities of the known DPPH, FRAP and ABTS were analyzed using CCA (Canoco 4.5).

\section{Results}

\section{Phenolic compounds and anthocyanins}

Eight phenolic compound markers were identified in plums fruit at $280 \mathrm{~nm}$. The acidic phenolics like caffeic acid, chlorogenic acid, ferulic acid and quercetin had more intense absorptance at $320 \mathrm{~nm}$ (Fig. 1). The concentration of the phenolic compounds of the 13 Prunus cultivars was shown in Table 1. The catechinic acid was the most abundant, especially in purple- or red-fresh cultivars Furongli, Xiguali and Yanzhili, which was two times higher than that 10 other cultivars. Additionally, abundant polyphenolic compounds were vanillic acid. Interestingly, the cultivars Xiguali, Gariota, Hongnai and Santa Rosa had outstanding high values of vanillic acid (Fig. 2). The hydroxycinnamic acid derivatives, caffeic acid, ferulic acid and chlorogenic in plums showed significant variation in 13 cultivars tested, in which caffeic acid predominated with the mean value of $7.68 \mu \mathrm{g} \cdot \mathrm{g}^{-1}$ fresh weight (FW). The acidic phenolics such as chlorogenic acid, ferulic acid and quercetin had low levels, and the neutral phenolic gallic acid tended to have low values as well. It should be noted that catechinic and syringic acids made $84.8 \%$ and $11.9 \%$ of the phenolic materials, respectively in Furongli.

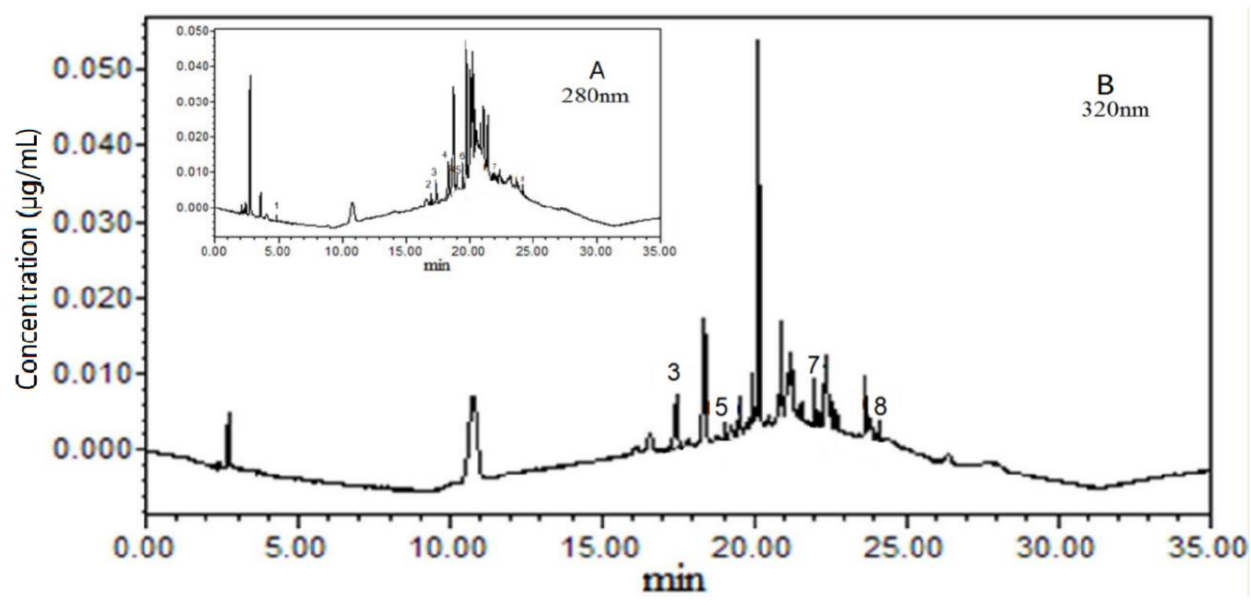

Figure 1. Chromatogram of 8 polyphenol at $280 \mathrm{~nm}$ (A) and $320 \mathrm{~nm}$ (B) of plum samples. (1) Gallic acid, (2) catechin acid, (3) caffeic acid, (4) vanillic acid, (5) chlorogenic acid, (6) syringic acid, (7) ferulic acid, (8) quercetin

Table 1. Correlation matrix between anthocyanins with chromatic parameters of plum cultivars

\begin{tabular}{c|c|c|c|c|c}
\hline & $\mathbf{L}^{*}$ & $\mathbf{a}^{*}$ & $\mathbf{b}^{*}$ & Chroma $(\mathbf{C})$ & Hue angle $(\mathbf{H})$ \\
\hline Cyanidin 3-O-glucoside & $-0.689 * *$ & $0.707 * *$ & $-0.738^{* *}$ & $-0.632 * *$ & $0.438^{* *}$ \\
Cyanidin 3-O-rutinoside & $-0.682^{* *}$ & $0.708^{* *}$ & $-0.736^{* *}$ & $-0.648^{* *}$ & $0.428^{* *}$ \\
Total anthocyanins & $-0.697 * *$ & $0.717 * *$ & $-0.748 * *$ & $-0.646 * *$ & $0.441^{* *}$ \\
\hline
\end{tabular}

$* * \mathrm{P}<0.01$ by Pearson's test 


$$
-3151-
$$

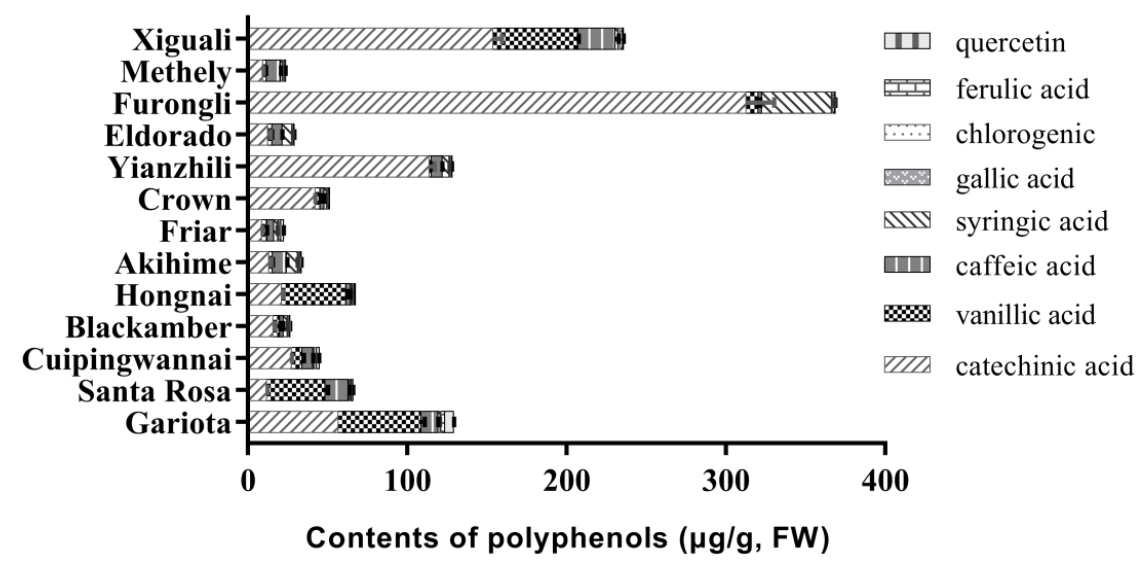

Figure 2. Contents of polyphenols in 13 plum cultivars ( $\mu \mathrm{g} / \mathrm{g} F W)$. The bars represent the mean \pm standard deviation

Concerning the anthocyanins content, we observed that cyanidin 3-O-glucoside quantities were two times higher than that of cyanidin 3-O-rutinoside in plums (Figs. 3 and 4). Cyanidin 3-O-glucoside was the predominant compound among anthocyanins and detected in Xiguali, Methely and Blackamber, which corresponds to a mean content of $335.0 \mathrm{mg} \cdot 100 \mathrm{~g} \mathrm{~g}^{-1} \mathrm{FW}$ among the 10 cultivars tested. The cyanidin 3-O-rutinoside was also detected in abundance and its mean value was $161.5 \mathrm{mg} \cdot 100 \mathrm{~g}^{-1} \mathrm{FW}$ in 10 cultivars. In all cases, the levels of cyanidin 3-O-glucoside, cyanidin 3-O-rutinoside and total anthocyanins correlated negatively or positively $(\mathrm{P}<0.01)$ with each of the color parameters $\mathrm{L}^{*}, \mathrm{a}^{*}, \mathrm{~b}^{*}, \mathrm{C}$ and $\mathrm{H}$, respectively (Table 1$)$. It seems that the highest values of $\mathrm{a}^{*}$ and $\mathrm{H}$ corresponded positively to the samples with the highest anthocyanins content. The lowest values of $\mathrm{b}^{*}, \mathrm{~L}^{*}$ and $\mathrm{C}$ were negatively correlated with the anthocyanin levels. The darker the fruits, the more negative was the correlation of the color parameters of $\mathrm{L}^{*}, \mathrm{~b}^{*}$ and $\mathrm{C}$ to the amount of total anthocyanins, cyanidin 3-Oglucoside and cyanidin 3-O-rutinoside in plums. These results showed that chromatic parameters have a significantly correlate with the evolution of fruit color and anthocyanins levels and indicated that color parameters could be used to monitor pigment evolution and anthocyanins content of plum cultivars.

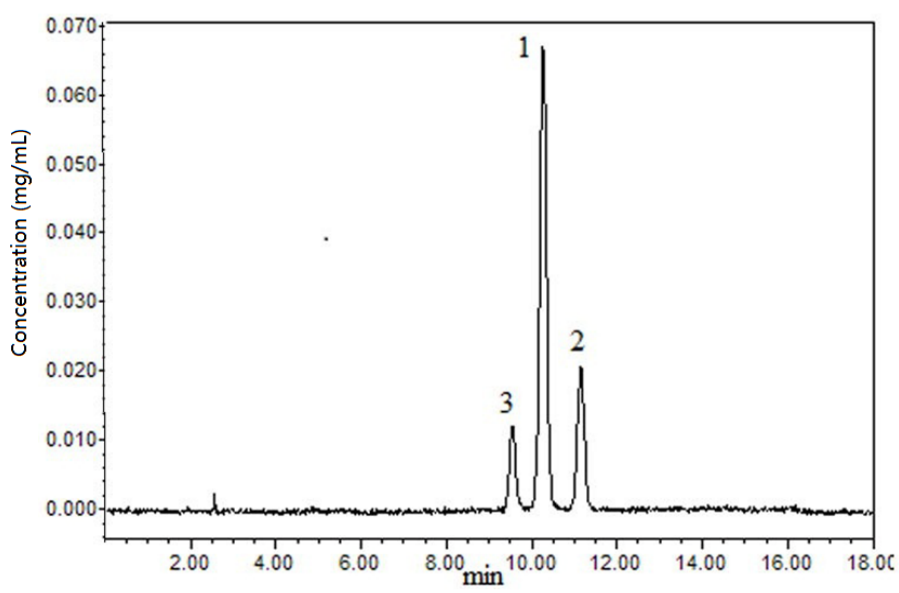

Figure 3. Chromatogram of anthocyanins of plum cultivars. (1) Cyanidin 3-glucoside, (2) cyanidin 3-rutinosid, (3) unknown 


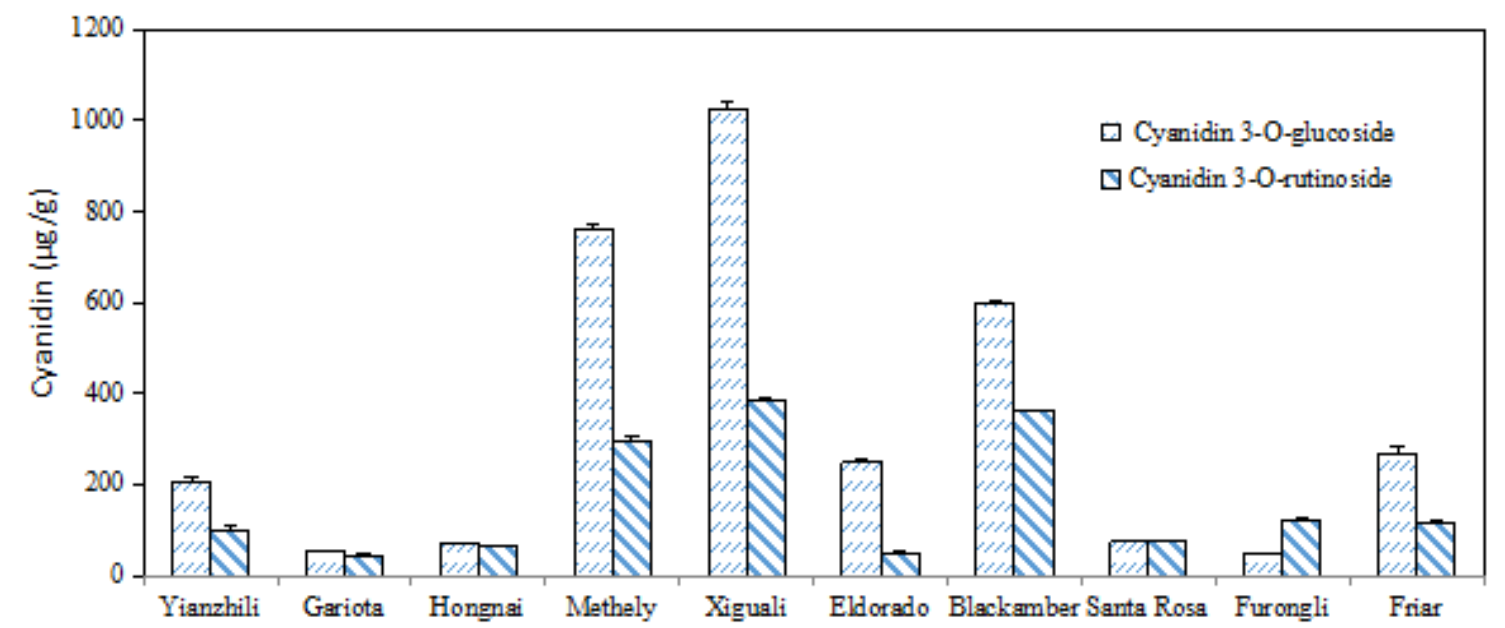

Figure 4. Anthocyanin contents in 10 plum cultivars. The bars represent the mean \pm standard deviation

\section{Total phenolics, ascorbic acid and antioxidant capacity}

Thirteen cultivars were analyzed with respect to their content of total phenolics, ascorbic acid and antioxidant capacities (Table 2). Total phenolic contents were classified into three categories: low (150-200 mg of gallic acid equivalent (GAE) per $100 \mathrm{~g} \mathrm{FW}$ ), medium (200-250 mg of GAE per $100 \mathrm{gFW}$ ) and high (> $250 \mathrm{mg}$ of GAE per $100 \mathrm{~g} \mathrm{FW}$ ). The highest contents of total phenolics were observed among the red- or purple-fresh fruits of Xiguali, Furongli and Yanzhili. The yellow-fresh fruits of Crown and Cuipingwannai had the lowest total phenolics except for Blackamber.

Table 2. Antioxidant capacity, total phenolic content and ascorbic acid content of 13 plum cultivars

\begin{tabular}{|c|c|c|c|c|c|}
\hline Cultivars & $\begin{array}{c}\text { Total phenolic } \\
\text { contents } \\
\left(\mathrm{mg} \cdot 100 \mathrm{~g}^{-1} \mathrm{Fw}\right)\end{array}$ & $\begin{array}{c}\text { Ascorbic acid } \\
\left(\mathrm{mg} \cdot 100 \mathrm{~g}^{-1} \mathrm{FW}\right)\end{array}$ & $\begin{array}{c}\text { DPPH } \\
(\%)\end{array}$ & $\begin{array}{c}\text { FRAP } \\
\left(\mu \mathrm{mol} \cdot \mathrm{g}^{-1} \mathrm{FW}\right)\end{array}$ & $\begin{array}{c}\text { ABTS } \\
(\%)\end{array}$ \\
\hline Gariota & $192.68 \pm 15.62 \mathrm{~cd}$ & $20.04 \pm 1.78 \mathrm{ef}$ & $93.95 \pm 0.31 \mathrm{c}$ & $10.51 \pm 1.53 b$ & $99.84 \pm 0.00 \mathrm{a}$ \\
\hline Santa Rosa & $229.38 \pm 9.29 b c$ & $29.31 \pm 1.03 c$ & $93.30 \pm 0.10 \mathrm{de}$ & $11.49 \pm 1.18 \mathrm{ab}$ & $99.63 \pm 0.08 \mathrm{a}$ \\
\hline Cuipingwannai & $174.82 \pm 16.03 \mathrm{~d}$ & $7.92 \pm 0.46 \mathrm{i}$ & $93.46 \pm 0.11 \mathrm{cde}$ & $8.17 \pm 1.64 c$ & $95.78 \pm 3.02 b$ \\
\hline Blackamber & $154.38 \pm 18.61 \mathrm{e}$ & $18.83 \pm 0.49 \mathrm{f}$ & $93.18 \pm 0.10 \mathrm{e}$ & $7.46 \pm 1.51 \mathrm{c}$ & $84.69 \pm 4.01 \mathrm{c}$ \\
\hline Hongnai & $216.74 \pm 29.49 c$ & $21.71 \pm 1.10 \mathrm{e}$ & $93.75 \pm 0.06 \mathrm{~cd}$ & $10.78 \pm 1.79 b$ & $99.68 \pm 0.23 a$ \\
\hline Akihime & $208.24 \pm 12.09 \mathrm{c}$ & $5.74 \pm 0.63 \mathrm{j}$ & $93.79 \pm 0.26 \mathrm{~cd}$ & $10.73 \pm 1.74 b$ & $99.20 \pm 0.57 \mathrm{a}$ \\
\hline Friar & $187.04 \pm 11.40 \mathrm{~cd}$ & $10.63 \pm 0.85 h$ & $92.49 \pm 0.41 \mathrm{f}$ & $4.79 \pm 0.82 \mathrm{~d}$ & $55.10 \pm 4.35 \mathrm{~d}$ \\
\hline Crown & $170.73 \pm 4.77 \mathrm{~d}$ & $12.16 \pm 0.24 \mathrm{~h}$ & $93.50 \pm 0.15 \mathrm{cde}$ & $7.77 \pm 1.46 \mathrm{~d}$ & $85.22 \pm 3.83 c$ \\
\hline Yanzhili & $257.53 \pm 16.57 \mathrm{~b}$ & $33.38 \pm 1.40 \mathrm{~b}$ & $94.52 \pm 0.00 \mathrm{~b}$ & $10.16 \pm 1.11 b$ & $99.44 \pm 0.33 \mathrm{a}$ \\
\hline Eldorado & $170.91 \pm 17.61 \mathrm{~d}$ & $16.85 \pm 0.63 g$ & $93.67 \pm 0.26 \mathrm{~cd}$ & $7.35 \pm 1.55 \mathrm{c}$ & $96.06 \pm 4.23 a$ \\
\hline Furongli & $281.05 \pm 9.59 \mathrm{a}$ & $21.78 \pm 1.32 \mathrm{e}$ & $94.48 \pm 0.11 b$ & $13.12 \pm 0.82 \mathrm{a}$ & $99.84 \pm 0.00 \mathrm{a}$ \\
\hline Methely & $206.94 \pm 6.91 c$ & $26.29 \pm 1.33 d$ & $93.71 \pm 0.21 \mathrm{~cd}$ & $11.74 \pm 0.64 b$ & $99.68 \pm 0.13 a$ \\
\hline Xiguali & $291.53 \pm 8.73 a$ & $44.00 \pm 1.82 \mathrm{a}$ & $96.14 \pm 0.25 \mathrm{a}$ & $12.12 \pm 1.12 \mathrm{ab}$ & $99.79 \pm 0.08 \mathrm{a}$ \\
\hline
\end{tabular}

Values represent mean \pm standard deviation $(n=3)$. Different letters denote significant differences in the level of $\mathrm{P}<0.05$ by Duncan's test 
In this study, 13 different cultivars were investigated for their total antioxidant capacity, using the DPPH, FRAP and ABTS methods as shown in Table 2. In general, the antioxidant activities of the black or red landraces Furongli and Xiguali were higher than those of the other cultivars. The results showed statistically significant correlation in antioxidant capacity on DPPH within 13 cultivars. The highest DPPH radical scavenging activities for the 13 cultivars fruit extracts was measured in Xiguali, followed by Furongli and Yanzhili, while the lowest values were observed in Friar. The reduction power towards ABTS radical cation was more than $95 \%$ in almost all plum cultivars except for Blackamber and Friar. The values obtained by FRAP were less than $10 \mu \mathrm{mol} \cdot \mathrm{g}^{-1} \mathrm{FW}$ for yellow-flesh cultivars like Crown, Cuipingwannai, Blackamber, Eldorada, and Friar. The FRAP values of red-flesh or red-skin cultivars were higher than those of yellow-flesh cultivars, except Akihime. In general, the measurement from the three methods (DPPH, ABTS and FRAP) demonstrated that Furongli and Xiguali had the highest levels of antioxidants but the lowest was in the Friar cultivar.

\section{Relationships between organic acids and sugars}

Correlation analysis of the typical biological characteristics on the components of sugar and organic acid in 13 plums cultivars (Table 3), found that, in terms of biological characteristics, succinic played a leading role, showed a extremely significantly positive correlation with Citric $\left(\mathrm{r}=0.98^{* *}\right)$ and sorbitol $(\mathrm{r}=0.54 *)$. In addition, Shikimic showed a significantly positive correlated with Cis-aconitic $\left(\mathrm{r}=0.59^{*}\right)$ and a significantly negatively correlated with Ascorbic $\left(r=-0.57^{*}\right)$. In the relationship in soluble sugars, sucrose, fructose and glucose were the main three sugars in plums, and there was a significant correlation among them. In addition, sorbitol and glucose were also significantly correlated $(\mathrm{r}=0.67 * *)$. It can be seen that the interdependent among soluble sugars is significantly stronger than that among organic acids, which may be due to a circulation of the metabolic pathways of these three sugars while not exist in organic acids. It is worth noting, the total phenolics and ascorbic indicated a significant positive correlation $\left(\mathrm{r}=0.76^{* *}\right)$.

Table 3. Correlation matrix between organic acids and sugars in 13 plum cultivars

\begin{tabular}{|c|c|c|c|c|c|c|c|c|c|c|c|}
\hline & Malic & Citric & Shikimic & Succinic & Fumaric & Cis-aconitic & Sucrose & Glucose & Fructose & \begin{tabular}{|l|} 
Sorbitol \\
\end{tabular} & Ascorbic \\
\hline Citric & -0.06 & & & & & & & & & & \\
\hline Shikimic & 0.24 & 0.27 & & & & & & & & & \\
\hline Succinic & -0.06 & $0.98 * *$ & 0.20 & & & & & & & & \\
\hline Fumaric & 0.41 & 0.34 & 0.40 & 0.37 & & & & & & & \\
\hline Cis-aconitic & 0.00 & -0.12 & $0.59 *$ & -0.15 & 0.36 & & & & & & \\
\hline Sucrose & 0.10 & 0.18 & -0.18 & 0.27 & -0.01 & -0.11 & & & & & \\
\hline Glucose & 0.25 & 0.09 & 0.35 & 0.14 & 0.05 & 0.00 & $0.75 * *$ & & & & \\
\hline Fructose & 0.29 & 0.14 & 0.46 & 0.17 & 0.14 & 0.29 & $0.70 * *$ & $0.97 * *$ & & & \\
\hline Sorbitol & 0.28 & 0.51 & 0.37 & $0.54^{*}$ & 0.17 & -0.35 & 0.52 & $0.67 * *$ & 0.65 & & \\
\hline Ascorbic & -0.21 & -0.53 & $-0.57 *$ & -0.44 & -0.47 & -0.21 & $0.55^{*}$ & 0.34 & 0.22 & -0.16 & \\
\hline Total phenolics & -0.13 & -0.47 & -0.45 & -0.42 & -0.45 & 0.22 & 0.37 & 0.04 & 0.03 & -0.28 & $0.76^{* * *}$ \\
\hline
\end{tabular}

$*$ and ** indicate correlated significantly at the level of $\mathrm{P}<0.05$ and $\mathrm{P}<0.01$ respectively

\section{Relationships between bioactive phytochemicals and antioxidant capacity}

The amount of total phenolics, ascorbic acid, individual phenolic compounds and anthocyanins showed a good linear relationship with each other (Table 4). The total phenolics and ascorbic acid concentration of the 13 plum cultivars correlated 
significantly with the antioxidant capacity detected by DPPH $\left(\mathrm{r}=0.78^{* *}, 0.73^{* *}\right)$ or FRAP $\left(\mathrm{r}=0.74^{* *}, 0.57^{*}\right)$, but not so significantly by ABTS $(\mathrm{r}=0.41,0.41)$. Moreover, there was a significant correlation between the total phenolic compounds and the ascorbic acid $\left(\mathrm{r}=0.76^{* *}\right)$. We found that catechinic acid had a stronger contribution to the antioxidant constituents than DPPH $\left(r=0.63^{*}\right)$, FRAP $\left(r=0.55^{*}\right)$ and the total phenolics $(\mathrm{r}=0.77 * *)$. The high significant correlations between caffeic acid and DPPH $\left(r=0.64^{*}\right)$, ascorbic acid $\left(r=0.64^{*}\right)$ and vanillic acid $\left(r=0.63^{*}\right)$ indicated that catechinic- and caffeic acids contributed more than ascorbic acid to the total phenolics and antioxidant activity. Cyanidin 3-O-glucoside also shows a significantly correlated $(\mathrm{r}=0.94 * *)$ with cyanidin 3-O-rutinoside in the flesh of plum cultivars (Fig. 5; Table 5). In addition, a positive significant correlation between the ascorbic acid, cyanidin 3-O-glucoside $(\mathrm{r}=0.63 *)$, and cyanidin 3-O-rutinoside $(\mathrm{r}=0.60 *)$ was identified. Anthocyanins were important bioactive compounds contributing to ascorbic acid. The clear trend between the antioxidant capacity and the Prunus genotypes was analyzed by Canonical correspondence analysis (CCA) (Fig. 5). The antioxidant capacity of the purple- or red-flesh cultivars Furongli, Xiguali and Yanzhili showed a bigger variation than that of the other cultivars and correlated with the contents of total phenolics (Fig. 5). In general, black and red Prunus cultivars had a higher antioxidant capacity compared with yellow-flesh genotypes such as Methely, Santa Rosa, Akihime, Crown, Hongnai, and Cuipingwannai (Table 4).
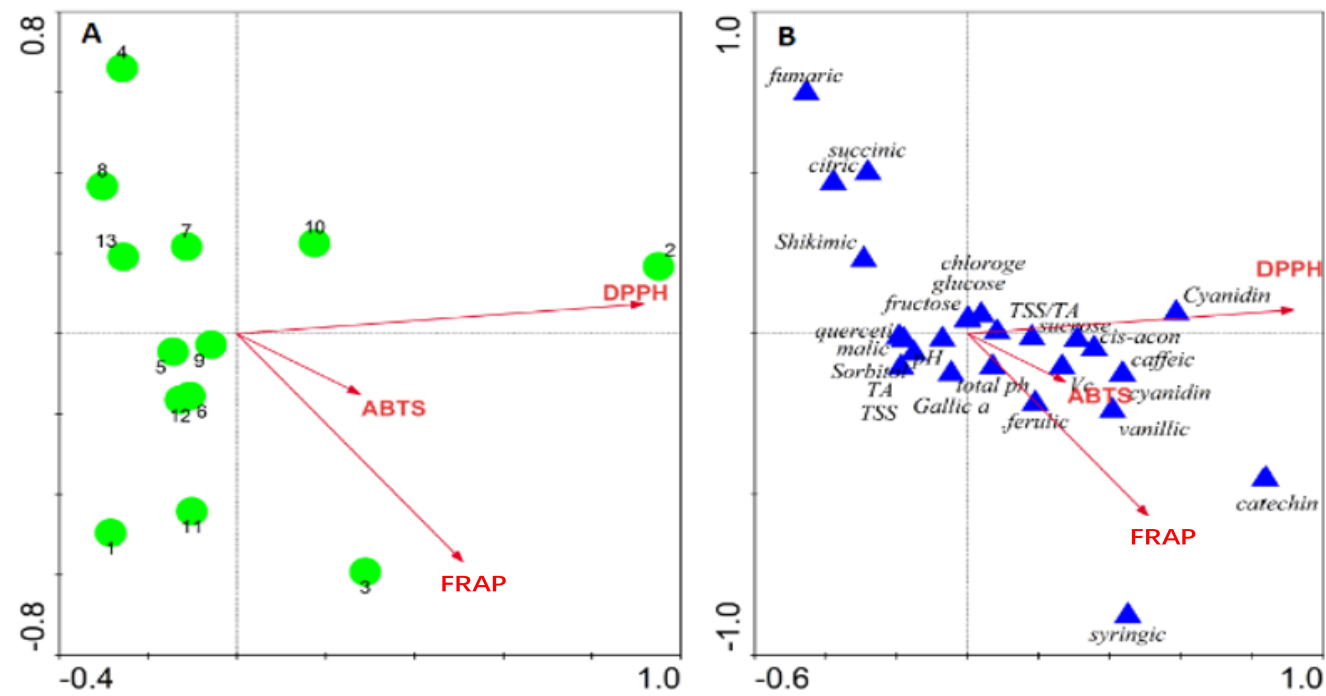

Figure 5. CCA ordination of the 13 plum cultivars (green circles) for the 29 phytochemical profiles (blue triangles), with respect to antioxidant capacities (red arrows) using DPPH, FRAP and ABTS methods

\section{Discussion}

The presence of polyphenolics correlated with previous investigations in which they showed that plums were rich in phenolic compounds and there are great differences among the phenolic contents in Prunus. Salicina and P. domestica (Arion et al., 2014; Mubarak et al., 2012; Slimestad et al., 2009). The occurrence of catechinic acid, vanillic acid and syringic acid has already been reported in plums (Jaiswal et al., 2013). However, some reports also showed smaller amounts of chlorogenic, caffeic acid and quercetin (Kim et al., 2003; Mubarak et al., 2012). 
Table 4. Correlation matrix between phenolic compounds, anthocyanins, total phenolics content, ascorbic acid and antioxidant capacities using $D P P H, F R A D$ and $A B T S$

\begin{tabular}{|c|c|c|c|c|c|c|c|c|c|c|c|c|c|c|}
\hline & $\begin{array}{c}\text { Gallic } \\
\text { acid }\end{array}$ & \begin{tabular}{|c|} 
Catechinic \\
acid
\end{tabular} & $\begin{array}{c}\text { Caffeic } \\
\text { acid }\end{array}$ & $\begin{array}{c}\text { Vanillic } \\
\text { acid }\end{array}$ & Chlorogenic & $\begin{array}{c}\text { Syringic } \\
\text { acid }\end{array}$ & $\begin{array}{c}\text { Ferulic } \\
\text { acid }\end{array}$ & Quercetin & \begin{tabular}{|l|} 
Cyanidin 3- \\
O-glucoside
\end{tabular} & \begin{tabular}{|c|} 
Cyanidin 3- \\
O-rutinoside
\end{tabular} & $\begin{array}{c}\text { Total } \\
\text { phenolics }\end{array}$ & $\begin{array}{c}\text { Ascorbic } \\
\text { acid }\end{array}$ & DPPH & FRAP \\
\hline Catechinic acid & -0.26 & & & & & & & & & & & & & \\
\hline Caffeic acid & 0.5 & 0.06 & & & & & & & & & & & & \\
\hline Vanillic acid & 0.29 & 0.1 & $0.63 *$ & & & & & & & & & & & \\
\hline Chlorogenic & -0.08 & 0.22 & 0.26 & 0.06 & & & & & & & & & & \\
\hline Syringic acid & -0.26 & $0.85^{* *}$ & -0.29 & -0.21 & -0.04 & & & & & & & & & \\
\hline Ferulic acid & 0.14 & 0.29 & 0.43 & $0.72 *$ & -0.17 & 0.1 & & & & & & & & \\
\hline Quercetin & -0.13 & -0.1 & 0.25 & 0.49 & -0.17 & -0.19 & $0.78 * *$ & & & & & & & \\
\hline Cyanidin 3-O-glucoside & 0.02 & 0.05 & 0.52 & 0.17 & 0.22 & -0.21 & 0.05 & -0.21 & & & & & & \\
\hline Cyanidin 3-O-rutinoside & -0.01 & 0.17 & 0.37 & 0.15 & 0.17 & -0.04 & 0.05 & -0.23 & $0.94 * *$ & & & & & \\
\hline Total phenolics & 0.2 & $0.77 * *$ & 0.48 & 0.36 & 0.23 & 0.48 & 0.32 & -0.25 & 0.33 & 0.39 & & & & \\
\hline Ascorbic acid & 0.06 & 0.39 & $0.65^{*}$ & 0.53 & 0.1 & -0.01 & 0.27 & -0.13 & $0.63^{*}$ & $0.6^{*}$ & $0.76 * *$ & & & \\
\hline DPPH & -0.02 & $0.63^{*}$ & $0.64 *$ & 0.46 & 0.42 & 0.23 & 0.33 & -0.09 & 0.46 & 0.39 & $0.78 * *$ & $0.73 * *$ & & \\
\hline FRAP & 0.09 & $0.55^{*}$ & 0.44 & 0.45 & 0.12 & 0.39 & 0.32 & -0.05 & 0.13 & 0.19 & $0.74 * *$ & $0.57 * *$ & $0.66 * *$ & \\
\hline ABTS & 0.13 & 0.28 & 0.36 & 0.34 & 0.17 & 0.15 & 0.07 & -0.02 & -0.01 & -0.02 & 0.41 & 0.41 & 0.59 & $0.81^{* *}$ \\
\hline
\end{tabular}

* and ** indicate correlated significantly at the level of $\mathrm{P}<0.05$ and $\mathrm{P}<0.01$ respectively

Table 5. Correlation matrix between anthocyanins with chromatic parameters of plum cultivars

\begin{tabular}{c|c|c|c|c}
\hline & $\mathbf{L}^{*}$ & $\mathbf{a}^{*}$ & $\mathbf{b}^{*}$ & Chroma (C) \\
\hline Cyanidin 3-O-glucoside & $-0.689^{* *}$ & $0.707 * *$ & $-0.738^{* *}$ & $-0.632^{* *}$ \\
Cyanidin 3-O-rutinoside & $-0.682^{* *}$ & $0.708^{* *}$ & $-0.736^{* *}$ & $-0.648^{* *}$ \\
Total anthocyanins & $-0.697 * *$ & $0.717^{* *}$ & $-0.748^{* *}$ & $-0.646^{* *}$ \\
\hline
\end{tabular}

$*$ and ** indicate correlated significantly at the level of $\mathrm{P}<0.05$ and $\mathrm{P}<0.01$ respectively

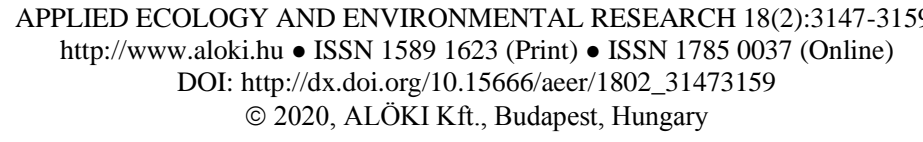


The plums contain mainly cyanidin 3-O-glucoside and cyaniding 3-O-rutinoside (Kim et al., 2003). Slimestad et al. (2009) reported that cyanidin 3-O-rutinoside represents more than $60 \%$ of the total anthocyanin content. It should be noted that cyanidin 3-Oglucoside and 3-O-rutinoside in fruit extracts of the yellow-flesh cultivars Crown, Akihime and Cuipingwannai were not detected due to their low contents, which is consistent to previous findings (Kim et al., 2003; Lozano et al., 2009).

The ascorbic acid content showed significant differences $(\mathrm{p}<0.05)$ in the 13 selected cultivars. The ascorbic acid detected in our experiments was higher rather than previous reports. Most of the fruits contained considerable amounts of ascorbic acid (Asami et al., 2003; Fang et al., 2017) which were higher than $10 \mathrm{mg} \cdot 100 \mathrm{~g}^{-1}$, and apparently higher than that in Spain (Gil et al., 2002). These results demonstrated that plum cultivars grown in subtropic areas have higher level of ascorbic acid than those grown in other regions.

Many assays were used for the determination of antioxidant activity in fruits and vegetables (Bustos et al., 2018; Moo-Huchin et al., 2015; Nayak et al., 2015).

These observations indicated that purple- or red-flesh Prunus cultivars had higher contents of the total phenolics (except cultivar Gariota) compared with other cultivars. However, Other researchers have also reported that plum is rich in total phenolic contents (Gil et al., 2002; Granato et al., 2018). Unfortunately, the range of total phenolics in plum differs among different reports due to their cultivar differences, agricultural practices, growth conditions and seasons (Arion et al., 2014; Kim et al., 2003).

These results indicated that the total phenolic compounds and ascorbic acid have a strong contribution to the antioxidant activity as also described in previous reports (Kim et al., 2003; Lozano et al., 2009; Mubarak et al., 2012). In some other reports, no correlation between antioxidant capacity and vitamin $\mathrm{C}$ was found (Hassimotto et al., 2005), even a negative influence of vitamin C was detected (Kalt et al., 1999). These similar results showed that cyanidin 3-O-rutinoside and cyanidin 3-O-glucoside were responsible for the pigmentation of the fruits (Kim et al., 2003; Raynal et al., 1989; Tomás-Barberán et al., 2001). These results were supported by previous reports which have shown that the main phytochemicals responsible for the antioxidant capacity in plums were total phenolics, ascorbic acid, and phenolic compounds (Gil et al., 2002; Vlaic et al., 2018), although other compounds may also be involved (Kim et al., 2003).

\section{Conclusion}

Overall, the results of this study demonstrated that many plum cultivars exhibited significant difference in levels of phenolic compounds, anthocyanins, total phenolics, ascorbic acid, and antioxidant capacities (DPPH, FRAP and ABTS). The highest levels of phenolic compounds, anthocyanins, and antioxidant capacities were observed in the black- or purple-flesh genotypes. Catechinic acid was the predominant polyphenolis in all tested plum cultivars and if combined with caffeic acid would make more important contributors to antioxidant capacities and total solute phenolic compounds, ascorbic acid in Japanese plums. The content of antioxidant capacities, polyphenols and anthocyanins has a certain correlation with the color of the peel and pulp, but it is not absolute, there were not found anthocyanins in yellow-skin or yellow-flesh cultivars. We conclude that phenolics, anthocyanin, and the antioxidant capacity could reflect the fruit quality and other important parameters for human health. It is not always a simple 
task to choose the most appropriate method to evaluate high-quality cultivars. Comparison of physicochemical characteristics and antioxidant profiles revealed that both introduced cultivars and landraces had good adaptability in the subtropical region. Thus, in order to achieve the maximum health-beneficial effects of plum consumption and their optimal organoleptic and nutritive properties, it would be advisable to get the cultivars with a high content of ascorbic acid, catechinic acid, caffeic acid, and syringic acid. The next work, we will conduct an depthly study on the main polyphenols and antioxidant activities in plums, and explore the best hybrid breeding model of plums to improve the functional components and nutrient content of fruits.

Acknowledgments. This work was funded by Fujian Agriculture Creative Projects from Fujian Development and Reform Commission, China (K6018203A), the Development of Local Science and Technology guided by central government, China (2017L3001) and the Project of Fujian Provincial Governor Fund.

\section{REFERENCES}

[1] Arion, M. C., Tabart, J., Kevers, C., Niculaua, M., Filimon, R., Beceanu, D., et al. (2014): Antioxidant potential of different plum cultivars during storage. - Food Chemistry 146: 485-491.

[2] Asami, D. K., Hong, Y.-J., Barrett, D. M., Mitchell, A. E. (2003): Comparison of the total phenolic and ascorbic acid content of freeze-dried and air-dried marionberry, strawberry, and corn grown using conventional, organic, and sustainable agricultural practices. Journal of Agricultural \& Food Chemistry 51(5): 1237-1241.

[3] Benzie, I. F., Strain, J. J. (1996): The ferric reducing ability of plasma (FRAP) as a measure of "antioxidant power": the FRAP assay. - Analytical Biochemistry 239(1): 7076.

[4] Bochi, V. C., Godoy, H. T., Giusti, M. M. (2015): Anthocyanin and other phenolic compounds in Ceylon gooseberry (Dovyalis hebecarpa) fruits. - Food Chemistry 176: 234-243.

[5] Bustos, M. C., Rocha-Parra, D., Rueda Sampedro, I., De Pascual-Teresa, S., León, Alberto E. (2018): The influence of different air-drying conditions on bioactive compounds and antioxidant activity of berries. - Journal of Agricultural and Food Chemistry acs.jafc.7b05395.

[6] Byrne, D. H., Sherman, W. B., Bacon, T. A. (2000): Stone Fruit Genetic Pool and Its Exploitation for Growing under Warm Winter Conditions. - In: Erez, A. (ed.) Temperate Fruit Crops in Warm Climates. Springer, Dordrecht.

[7] Cefali, L. C., Maia, L., Stahlschimidt, R., Ataide, J. A., Tambourgi, E. B., Rosa, P. C. P., et al. (2018): Vitamin $C$ in acerola and red plum extracts: quantification via hplc, in vitro antioxidant activity, and stability of their gel and emulsion formulations. - Journal of AOAC International 101(5): 1461-1465.

[8] Dai, J., Mumper, R. J. (2010): Plant phenolics: extraction, analysis and their antioxidant and anticancer properties. - Molecules 15(10): 7313-7352.

[9] Fang, T., Zhen, Q., Liao, L., Owiti, A., Zhao, L., Korban, S. S., et al. (2017): Variation of ascorbic acid concentration in fruits of cultivated and wild apples. - Food Chemistry 225: 132-137.

[10] Fanning, K. J., Topp, B., Russell, D., Stanley, R., Netzel, M. (2014): Japanese plums (Prunus salicina Lindl.) and phytochemicals - breeding, horticultural practice, postharvest storage, processing and bioactivity. - Journal of the Science of Food and Agriculture 94(11). 
[11] Gil, M. I., Tomás-Barberán, F. A., Hess-Pierce, B., Kader, A. A. (2002): Antioxidant capacities, phenolic compounds, carotenoids, andvitamin c contents of nectarine, peach, and plum cultivarsfrom california. - Journal of Agricultural and Food Chemistry 50(17): 4976-4982.

[12] Glew, R. H., Ayaz, F. A., Sanz, C., Vanderjagt, D. J., Huang, H. S., Chuang, L. T., et al. (2003): Changes in sugars, organic acids and amino acids in medlar (mespilus germanica 1.) during fruit development and maturation. - Food Chemistry 83(3): 363-369.

[13] Goodarzi, S., Rafiei, S., Javadi, M., Haghighian, H. K., Noroozi, S. J. J. o. N. (2018): A review on antioxidants and their health effects. - Security 3: 106-112.

[14] Granato, D., Shahidi, F., Wrolstad, R., Kilmartin, P., Melton, L. D., Hidalgo, F. J., et al. (2018): Antioxidant activity, total phenolics and flavonoids contents: should we ban, in vitro, screening methods? - Food Chemistry 264: 471-475.

[15] Hassimotto, N. M. A., Genovese, M. I., Lajolo, F. M. J. J. o. A., F. (2005): Antioxidant activity of dietary fruits, vegetables, and commercial frozen fruit pulps. - Food Chemistry 53: 2928-2935.

[16] Jaiswal, R., Karaköse, H., Rühmann, S., Goldner, K., Kuhnert, N. (2013): Identification of phenolic compounds in plum fruits (Prunus salicina L. and Prunus domestica L.) by high-performance liquid chromatography/tandem mass spectrometry and characterization of varieties by quantitative phenolic fingerprints. - Journal of Agricultural \& Food Chemistry 61(49).

[17] Jiao, Z., Deng, J., Li, G., Zhang, Z., Cai, Z. (2010): Study on the compositional differences between transgenic and non-transgenic papaya (Carica papaya L.). - Journal of Food Composition and Analysis 23(6): 640-647.

[18] Kalt, W., Forney, C. F., Martin, A., Prior, R. L. (1999): Antioxidant capacity, vitamin C, phenolics, and anthocyanins after fresh storage of small fruits. - Journal of Agricultural and Food Chemistry 47(11): 4638-4644.

[19] Kelebek, H., Selli, S., Gubbuk, H., Gunes, E. (2015): Comparative evaluation of volatiles, phenolics, sugars, organic acids and antioxidant properties of sel-42 and tainung papaya varieties. - Food Chemistry 173: 912-919.

[20] Kim, D. O., Chun, O. K., Kim, Y. J., Moon, H. Y., Lee, C. Y. (2003): Quantification of polyphenolics and their antioxidant capacity in fresh plums. - Journal of Agricultural and Food Chemistry 51(22): 6509-6515.

[21] Li, P., Wu, W., Chen, F., Liu, X., Lin, Y., Chen, J. J. H. (2015): Prunus salicina 'Crown', a yellow-fruited Chinese Plum. - HortScience 50(12): 1822-1824.

[22] Liu, R. H. (2013): Health-promoting components of fruits and vegetables in the diet. Advances in Nutrition: An International Review Journal 4(3): 384S-392S.

[23] Liu, W., Liu, D., Zhang, A., Feng, C., Yang, J., Yoon, J., et al. (2007): Genetic diversity and phylogenetic relationships among plum germplasm resources in china assessed with inter-simple sequence repeat markers. - Journal of the American Society for Horticultural Science 132(5): 619-628.

[24] Lozano, M., Vidalaragon, M. C., Hernandez, M. T., Ayuso, M. C., Bernalte, M. J., Garcia, J., Velardo, B. (2009): Physicochemical and nutritional properties and volatile constituents of six Japanese plum (Prunus salicina Lindl.) cultivars. - European Food Research and Technology 228(3): 403-410.

[25] Rufino, M. S., Alves, R. E., De Brito, E. S., Perezjimenez, J., Sauracalixto, F., Mancinifilho, J. (2010): Bioactive compounds and antioxidant capacities of 18 nontraditional tropical fruits from Brazil. - Food Chemistry 121(4): 996-1002.

[26] Mirmiran, P., Noori, N., Zavareh, M. B., Azizi, F. (2009): Fruit and vegetable consumption and risk factors for cardiovascular disease. - Metabolism Clinical and Experimental 58(4): 460-468.

[27] Moohuchin, V. M., Moohuchin, M. I., Estradaleon, R. J., Cuevasglory, L., Estradamota, I., Ortizvazquez, E., ... Sauriduch, E. (2015): Antioxidant compounds, antioxidant activity 
and phenolic content in peel from three tropical fruits from Yucatan, Mexico. - Food Chemistry 166: 17-22.

[28] Mubarak, A., Swinny, E. E., Ching, S. Y. L., Jacob, S. R., Lacey, K., Hodgson, J. M., et al. (2012): Polyphenol composition of plum selections in relation to total antioxidant capacity. - Journal of Agricultural and Food Chemistry 60(41): 10256-10262.

[29] Nayak, B., Liu, R. H., Tang, J. (2015): Effect of processing on phenolic antioxidants of fruits, vegetables, and grains - a review. - C R C Critical Reviews in Food Technology 55(7): 887-918.

[30] Raynal, J., Moutounet, M., Souquet, J. M. (1989): Intervention of phenolic compounds in plum technology. 1. Changes during drying. - Journal of Agricultural and Food Chemistry 37(4): 1046-1050.

[31] Slimestad, R., Vangdal, E., Brede, C. (2009): Analysis of phenolic compounds in six norwegian plum cultivars (Prunus domestica L.). - Journal of Agricultural and Food Chemistry 57(23): 11370-11375.

[32] Tomasbarberan, F. A., Gil, M. I., Cremin, P., Waterhouse, A. L., Hesspierce, B., Kader, A. A. (2001): HPLC-DAD-ESIMS Analysis of phenolic compounds in nectarines, peaches, and plums. - Journal of Agricultural and Food Chemistry 49(10): 4748-4760.

[33] Turturică, M., Stănciuc, N., Mureșan, C., Râpeanu, G., Croitoru, C. (2018 Thermal degradation of plum anthocyanins: comparison of kinetics from simple to natural systems. - Journal of Food Quality. https://doi.org/10.1155/2018/1598756.

[34] Usenik, V., Kastelec, D., Veberi, R., Tampar, F. (2008): Quality changes during ripening of plums (Prunus domestica L.). - Food Chemistry 111(4): 830-836.

[35] Vlaic, R. A., Muresan, V., Muresan, A. E., Muresan, C., Paucean, A., Mitre, V., ... Muste, S. (2017): The changes of polyphenols, flavonoids, anthocyanins and chlorophyll content in plum peels during growth phases: from fructification to ripening. - Notulae Botanicae Horti Agrobotanici Cluj-Napoca 46(1): 148-155.

[36] Wang, R., Wang, L., Yuan, S., Li, Q., Pan, H., Cao, J., Jiang, W. (2018): Compositional modifications of bioactive compounds and changes in the edible quality and antioxidant activity of 'Friar' plum fruit during flesh reddening at intermediate temperatures. - Food Chemistry 254: 26-35.

\section{APPENDIX}

Table A1. The dates of collecting samples in this work

\begin{tabular}{c|c}
\hline Cultivar & Time \\
\hline Xiguali & $6 / 20 / 2018$ \\
Methely & $7 / 25 / 2018$ \\
Furongli & $8 / 5 / 2018$ \\
Eldorado & $7 / 25 / 2018$ \\
Yianzhili & $6 / 8 / 2018$ \\
Crown & $8 / 5 / 2018$ \\
Friar & $7 / 25 / 2018$ \\
Akihime & $8 / 10 / 2018$ \\
Hongnai & $8 / 10 / 2018$ \\
Blackamber & $8 / 10 / 2018$ \\
Cuipingwannai & $8 / 20 / 2018$ \\
Santa Rosa & $7 / 25 / 2018$ \\
Gariota & $7 / 20 / 2018$ \\
\hline
\end{tabular}

